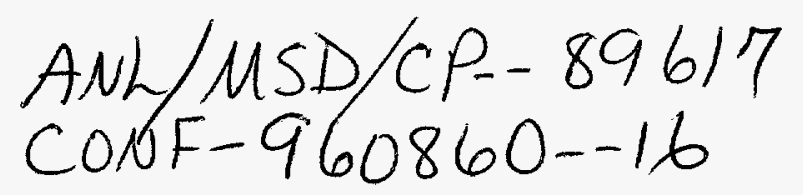

EFFECT OF ELECTRON IRRADIATION ON THE 3C-4H TRANSFORMATION IN A Co-Fe ALLOY*

Charles W. Allen

Materials Science Division

Argonne National Laboratory

Argonne, IL 60439

Hirotaro Mori

Research Center for UHVEM

Osaka University, Suita

Osaka 565 Japan

RECEIVED

JUL 181996

OSTI

March 1996

The submitted manuscript has been authored by a contractor of the U.S. Government under contract No.

W-31-109-ENG-38. Accordingly, the U.S. Government retains a nonexclusive, royalty-free license to publish or reproduce the published form of this contribution, or allow

others to do so, for U.S. Government purposes.

Submitted to the Microscopy Society of America Annual Meeting, August 11-15, 1996, Minneapolis, MN.

*Work supported by the U. S. Department of Energy, BES-Materials Sciences, under Contract W-31-109-Eng-38. 


\section{DISCLAIMER}

This report was prepared as an account of work sponsored by an agency of the United States Government. Neither the United States Government nor any agency thereof, nor any of their employees, makes any warranty, express or implied, or assumes any legal liability or responsibility for the accuracy, completeness, or usefulness of any information, apparatus, product, or process disclosed, or represents that its use would not infringe privately owned rights. Reference herein to any specific commercial product, process, or service by trade name, trademark, manufacturer, or otherwise does not necessarily constitute or imply its endorsement, recommendation, or favoring by the United States Government or any agency thereof. The views and opinions of authors expressed herein do not necessarily state or reflect those of the United States Government or any agency thereof. 


\title{
EFFECT OF ELECTRON IRRADIATION ON THE 3C-4H TRANSFORMATION IN A CO-Fe ALLOY
}

\author{
Charles W. Allen • and Hirotaro Mori ** \\ *Materials Science Division, Argonne National Laboratory, Argonne, IL 60439 USA \\ **Research Center for UHVEM, Osaka University, Suita, Osaka 565 Japan
}

In general, irradiation of materials by high energy electrons, protons or neutrons has been shown to stabilize the existing microstructure against subsequent martensitic transformation. Alloys which have been studied include the binary intermediate phases $\mathrm{NiTi}[2,3]$ and $\mathrm{Ni}_{63} \mathrm{Al}_{37}[4]$ and ternary phases between $\mathrm{Cu}_{37.5} \mathrm{Al}_{62.5}$ and $\mathrm{Cu}_{63.6} \mathrm{Al}_{36.4}[5,6]$ as well as the intermetallic $\mathrm{Cu}_{69.01} \mathrm{Al}_{17.92} \mathrm{Zn}_{12.17}[7,8,9]$. In these materials, the martensitic transformations are known to be sensitive to small changes in chemical composition and to the degree of long range order. In addition, one should expect the kinetics of martensitic transformations to be sensitive to other forms of structural damage introduced during irradiation also. This spectrum of irradiation-induced phenomena renders the interpretation of results in studies of such concentrated binary and temary phases rather complicated, therefore.

We present here the preliminary results of a study of the effect of electron irradiation on the character of the martensitic transformation in a relatively dilute terminal solid solution of $\mathrm{Co}+5.75$ wt pct Fe, similar in composition to that employed for studies of the transformation mechanism itself [10]. The effect of the solute Fe is to depress the equilibrium Co-transformation temperature and to modify the transformation, which in $\mathrm{Co}_{\mathrm{s}} \mathrm{fcc}-\mathrm{hcp}$, to one of the type fcc-dhcp; that is, the transformation is between the threelayer stacking sequence of the cubic structure $(A B C)$, known as $3 C$, and the four-layer stacking sequence of the di-hexagonal structure $(A B A C)$, known as $4 \mathrm{H}$. The transformation involves only the glide of groups of Shockley-like partial dislocations $[10,11,12]$ and is one of the family of simple martensitic transformations often called shear transformations. While electron irradiation may modify to some extent the degree of short range order in such an alloy, its predominant effect is surely the formation of faulted Frank-type dislocation loops, which may be expected to impede the shear transformations (that is, to stabilize the existing structure) by acting as barriers to the glide of the necessary transformation dislocations. The effect of the presence of Frank loops on nucleation of such a transformation is perhaps less predictable. The loops enclose intrinsic or extrinsic stacking faults, the introduction of which is the structural essence of the transformation. However, the irradiation-induced loops themselves are sessile; that is, the transformation cannot propagate by glide of the loops in the fault plane; only by climb. The transformation occurring in this manner would not be martensitic.

The subject alloy was prepared by arc melting and hot rolling by the Materials Preparation Center of Ames Laboratory. $3 \mathrm{~mm}$ disks were cut by EDM, lapped to about $200 \mathrm{~mm}$ thickness, annealed for $2 \mathrm{~h}$ at $915^{\circ} \mathrm{C}$ in an evacuated Vicor tube and air cooled to room temperature, resulting in predominantly $3 \mathrm{C}$ material. Some of the specimens were subsequently quenched in $\mathrm{LN}_{2}$ to produce a significant volume fraction the $4 \mathrm{H}$ structure within $3 \mathrm{C}$. Thin foils were prepared by jet thinning at $-15^{\circ} \mathrm{C}$ in a perchloric acidalcohol electrolyte.

Preliminary experiments were performed at the Research Center for Ultra-High Voltage Electron Microscopy at Osaka University. The threshold of electron energy to produce displacement damage in this alloy is estimated to be between 400 and $500 \mathrm{kV}$. At an electron energy of $2 \mathrm{MeV}$, the displacement cross-section for electron damage in this material is approximately 75 barns ( 1 barn $=10^{-24} \mathrm{~cm}^{2}$ ). Heating of one of the quenched specimens (large volume fraction of $4 \mathrm{H}$ ) in an Hitachi $\mathrm{H}-800 \mathrm{~B}$ operated at $200 \mathrm{kV}$ (well below threshold for displacement damage) revealed that the $4 \mathrm{H}-3 \mathrm{C}$ transformation occurred over the range $120-400^{\circ} \mathrm{C}$ in the electron transparent areas of the specimen. A similar specimen was subjected to $2 \mathrm{MeV}$ electron irradiation (well above threshold for displacement damage) in the Hitachi H-3000 at room temperature for more than $1 \mathrm{~h}$ with the electron beam substantially defocussed over the entire electron transparent region. The specimen was subsequently heated but failed to observably transform until about $600^{\circ} \mathrm{C}$. A specimen which was initially predominantly $3 \mathrm{C}$ was irradiated in a similar manner also at room temperature, followed by cooling in an Oxford helium-cooled double tilt holder. No transformation to the $4 \mathrm{H}$ structure was observed in this specimen even on cooling to an indicated temperature of $16 \mathrm{~K}$. Both experiments seem to demonstrate qualitatively the profound effect that the damage structure produced by electron irradiation can have on these simple martensitic transformations. In the interpretation of results of related earlier studies involving intermetallics, the 
contribution of irradiation-induced structural defects (not associated with disordering) to the stabilization phenomenon was totally ignored, which, in view of the qualitative results presented here, seems to be thoroughly unjustified.

A more thorough study of this phenomenon is being pursued which attempts to quantify the transformation retardation effect. The major problem in doing so stems from the well known fact that such martensitic transformations are significantly retarded due to surface relaxation and possibly surface contamination effects in thin regions of foil specimens.

\section{Acknowledgment}

The preliminary experiments in this study were performed under a Japan Society for the Advancement of Science (Short Term) Fellowship (CWA) in the Research Center for Ultra-High Voltage Electron Microscopy, Osaka University. One of he authors is grateful to Professors H. Mori and H. Nishihara of UHVEM Center for their hospitality during this brief visit and to Bernard Kestel of Argonne National Laboratory for his indispensible assistance in the TEM specimen preparation.

\section{References}

1. Electron Microscopy Center for Materials Research is supported by U. S. Department of Energy, BES-Materials Sciences, under Contract W-31-109-Eng-38.

2. T. Hoshiya, T. S. Den, H. Ito, H. Itami, and S. Takamura, 1986, Proceedings of the International Conference on Martensitic Transformations 1986 (Japan Institute of Metals), p. 685.

3. K. Tsuchiya and S. Ohnuki, Private Communications.

4. S. Muto and D. Schryvers, J. Alloys and Compounds, 199 (1993) 1-6.

5. Y. Nakata,T. Tadaki, and K. Shimizu, International Meeting on Advances in Materials (Pittsburgh, PA: Materials Research Society, vol. 9) p. 231.

6. K. Tsuchiya and K. Marukawa, Proceedings of the International Symposium on Shape Memory Materials (Beifing: Intemational Academic Publishers, 1994) 314-318.

7. A. Tolley and M. Ahlers, Scripta Metall., 23 (1989) 2117.

8. A. Tolley, Radiat. Effects Defects Solids, 128 (1994) 229.

9. A. Tolley, Mi-P. Macht, M. Müller, C. Abromeit and H. Wollenberger, Phil. Mag. A, 72 (1995) 16331647.

10.T. Waitz and H. Karnthaler, Phil. Mag. A, in press.

11.C. Allen and K. Liao, Phys. Stat. Sol. (a), 74 (1982) 673.

12.C. W. Allen, H. R. Kolar and J. C. H. Spence, Proceedings of the International Conference on

Martensitic Transformations 1986 (Japan Institute of Metals) 186-191. 